\title{
Battery Insulation Performance Analysis in Electric Vehicles for the Improvement of Battery Lifetime
}

\author{
Lora Khaula Amifia ${ }^{1}$, Nuansa Dipa Bismoko ${ }^{2}$, Philip Tobianto Daely ${ }^{3}$ \\ ${ }^{1}$ Faculty of Electrical Engineering and Intelligent Industry, Institut Teknologi Telkom Surabaya, J1. Ketintang Selatan No.156, \\ Ketintang, Gayungan, Surabaya, East Java, Indonesia \\ ${ }^{2}$ Internet of Things Division, PT. Telekomunikasi Seluler (Telkomsel), The Telkom Hub, Jl. Gatot Subroto No.Kav. 52, Kuningan Barat, \\ Mampang Prapat, South Jakarta, DKI Jakarta, Indonesia \\ ${ }^{3}$ Department of IT Convergence Engineering, Kumoh National Institute of Technology, Gumi, South Korea
}

\begin{tabular}{l} 
ARTICLE INFO \\
\hline Article history: \\
Received October 29, 2021 \\
Revised November 22, 2021 \\
Accepted December 05, 2021 \\
\hline
\end{tabular}

\section{Keywords:}

Lithium Polymer Battery;

Fault Detection;

Fault Isolation;

Battery Modelling

\begin{abstract}
The battery is the main component both as an energy provider and as an interface for several systems in an electric vehicle. It has three important parameters: current, voltage, and temperature that must be maintained as the battery can have a harmful reaction that can lead to overcurrent. The battery must also not overcharging or discharging for too long because it can cause damage and affect its lifetime. Another error that can arise is sensor failure due to the interference or noise that can cause an error in data reading. To prevent this problem, it needs protection by means of isolation in operating the battery. In this research, planning in optimizing battery work was conducted by designing the process of detection and isolation of faults that occurred in batteries, particularly lithium polymer battery to reach their more optimal and good performance. Battery modeling was needed as the parameter identification, and the Kalman Filter algorithm was applied to help to reduce the detection rate and fault isolation. The results of detection and isolation of overcurrent and sensor failure using Kalman Filter were found quite accurate. In overcurrent isolation, a discharge current of $6 \mathrm{~A}$ was obtained from the maximum current limit of $10 \mathrm{~A}$, and for sensor failure isolation, the Kalman Filter algorithm succeeded in improving the results of the previous reading.
\end{abstract}

This work is licensed under a Creative Commons Attribution-Share Alike 4.0

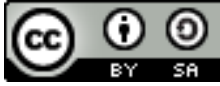

\section{Corresponding Author:}

Lora Khaula Amifia, Faculty of Electrical Engineering and Intelligent Industry, Institut Teknologi Telkom Surabaya, J1. Ketintang Selatan No.156, Ketintang, Gayungan, Surabaya, East Java, Indonesia Email: loraamifia@ittelkom-sby.ac.id

\section{INTRODUCTION}

The use of the electric vehicle is predicted to rapidly increase threefold by 2025 . Today, there have been many electric vehicle manufacturers developing any kind of technology to support their achievement. The electric vehicle is one of the vehicles that is getting more popular in public - particularly in Indonesia, and there are some institutions producing and enjoying its technology features. Interestingly, energy charging uses batteries by storing electrical energy [1]. Here, the battery is one of the main things since it is a supporting factor for this success. It has critical capabilities, one of which is to monitor the state and detect the level of current, voltage, and temperature [2]. The battery can control the recharge process, regulate how much voltage and current are used, control temperature, and store important information [3][4].

The research background is the most important thing in battery performance is how to maintain a good and long lifetime. Battery should always be frequently monitored as the exposure because vulnerabilities can occur at any time, such as overcharging or over-discharging, or even sensor failure [5]. The fault isolation and control algorithm of a battery is highly dependent upon the process of measuring voltage, current, and temperature [6]. These three elements determine success in identifying battery parameters [7]. Fault detection and isolation of battery are developed using an adaptive model estimation using the Kalman Filter algorithm 
to estimate the parameters of each model to generate a residual signal, which is then used to detect and isolate any faults in the battery [8][9]. Any faults in the sensors can also hinder the battery operation and greatly determine the battery life. In this case, an optimal design concept is highly required to well maintain the battery life.

The other related work from the past research is as follows; the isolation and estimation of faults in batteries could do healthy monitoring [10]. The design to find out the fault source and provide an estimation of isolation fault can realize the simultaneous fault isolation as well as estimation of the battery [11]. In another case, as shown by the simulation results, it was stated that the Learning Observers method was effective in detecting the faults errors, but there were still some weaknesses in the decision-making process [12][13][14]. In addition, another very important part of fault detection and isolation is battery modeling to facilitate the understanding of battery characteristics [15]. The battery model is the best choice in assisting the estimation, optimization process, and fault detection and isolation process.

There are two contributions in this study; optimizing SOC performance by analyzing the SOC-OCV relationship curve in several tests (Constant Load Discharge, Pulse, and Varied Load) and analyzing lithium polymer battery faults in electric vehicles to increase battery life. This design is a method to prevent the battery from being rapidly damaged, lengthen the battery lifetime, and optimize the performance of the battery in system management when facing any faults.

\section{METHOD}

The methodology developed in this study consists of a system design of fault detection and isolation and battery modeling. Overall battery modeling has been unified in optimizing the fault isolation of Lithium Polymer batteries to increase battery life.

\subsection{Fault Detection and Isolation}

A fault is an abnormal condition that might or might not cause the system failure. Meanwhile, failure is a permanent disruption of the system's ability to perform the functions required under certain operating conditions [16]. In turn, in this study, the fault isolation process was determined to overcome any faults and failures in the system, specifically in the lithium polymer battery. The fault occurs as a system does not optimally work in the system operation. The faults detected in this study were overcurrent and sensor failure, which can greatly affect battery life [17][18]. Fault detection depends on sensor input coming from the performance of current, voltage, and temperature on a lithium polymer battery that has been integrated with the system [19].

Fault detection and isolation are needed by the system to enable the battery to work accurately and optimally. Also, it is to make the system performance manageable as optimal as possible to maintain the battery life better. For the fault diagnosis, it can be concluded that to detect the faults in real-time as soon as possible was regarding overcurrent and sensor failure [20]. Meanwhile, fault isolation was conducted by finding out the cause of the overcurrent and sensor failure by isolating any parameters that ran abnormally, and then it was continued with the identification to estimate the size and characteristics of the faults [21]. Furthermore, the system would provide the mechanism of hardware and software architecture that enabled to reach a certain goal - not only in a normal operation but also in fault situations [22][23].

In the operation of the lithium polymer battery in this study, the maximum current, voltage, and temperature capacities were determined and tested. When the work of current, voltage, and temperature exceeded the maximum capacity, fault detection worked. In addition, fault detection worked when tuning was not optimal on the controller part, errors in sensor calibration.

\subsection{Lithium Polymer Battery}

Lithium batteries are the most widely used and easy to find because they have several features, namely high voltage, high energy density, minimum self-discharge, and long cycle life. These battery characteristics make Lithium-based batteries widely used in various applications such as portable devices, energy storage systems, and electric vehicles. This study uses a lithium polymer battery as the main object consisting of three cells of $2200 \mathrm{mAh}$ with a maximum voltage of 12.6 Volts and a maximum loading on each cell of $25 \mathrm{C}-35 \mathrm{C}$ or 55 - 77 Ampere. The physical form of the Li-Po battery can be seen in Fig. 1. Lithium Polymer Battery Specification is shown in Table 1. Lithium Polymer batteries have much better durability, especially when hot compared to Lithium-Ion. The material is made of polymer compounds, so the shape can be flexible. The nominal voltage of a single cell Li-Po battery is 3.7 volts. 


\subsection{System Design}

In this study, the main thing that needs to be done is to determine the battery modeling, which previously identified the parameters through several battery tests. Data retrieval is done by testing the battery by providing the desired input or input and then recording the output or output with various tests carried out to achieve an error detection algorithm on the battery. After obtaining the appropriate battery modeling and obtaining the desired battery data, the next step is to make a simulation based on the model. The research simulation used comparison material from experimental data, and by experimentation, it can be seen how successful the method used was. Fault, in this case, was not seen as a failure in the work of the hardware. The block diagram in this study is presented in Fig. 2.

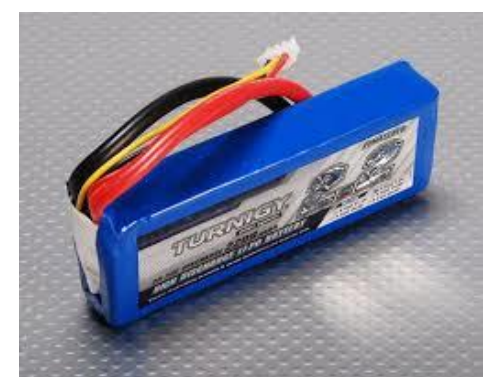

Fig. 1. Lithium Polymer Battery Physical

Table 1. Lithium Polymer Battery Specification

\begin{tabular}{lc}
\hline \multicolumn{1}{c}{ Parameter } & Value \\
\hline Capacity & $2200 \mathrm{mAh}$ \\
Max Discharge Current & $45 \mathrm{~A}$ \\
Max Charge Rate Current & $4.34 \mathrm{~A}$ \\
Charge Limit Voltage & $4.234 \mathrm{~V}$ \\
Discharge Limit Voltage & $2.3 \mathrm{~V}$ \\
\hline
\end{tabular}

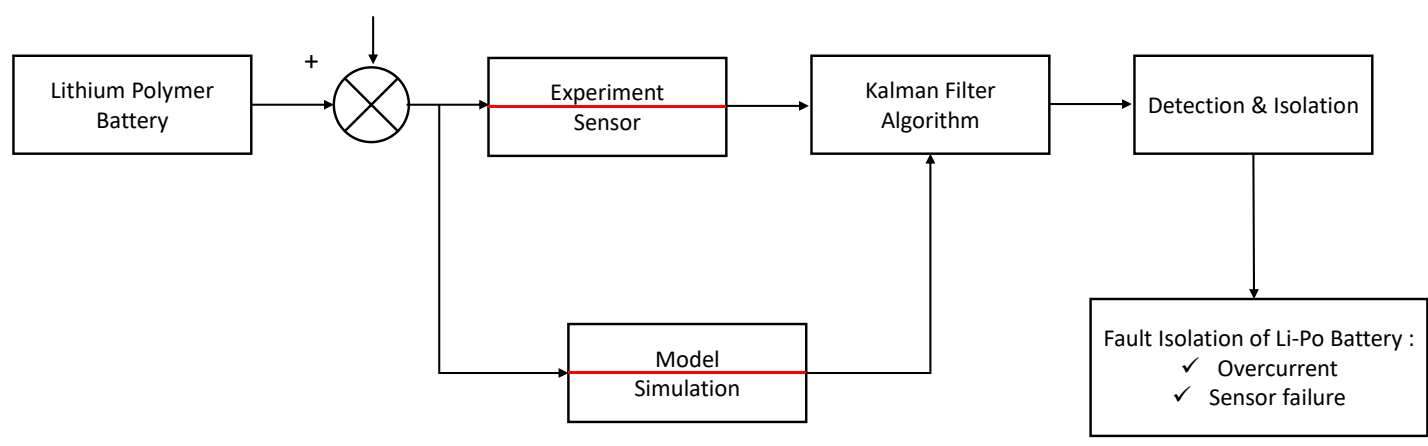

Fig. 2. Diagram Block of Fault Detection and Isolation of Battery

The main object in this study was a battery containing two important elements: current and voltage, which were then examined for their characteristics from several experiments that have been designed [24]. An important part before detection was to create experimental data directly from sensors and model or simulation data [25]. The two data were compared using the Kalman Filter algorithm so as to produce a decision on the detection of a battery state. Fault detection included overcurrent, overvoltage, over-discharging, and sensor failure, each of which could not be separated from any interference or noise [10][19].

The design of the fault isolation algorithm on the battery is by applying the If-Then rules. If the capacity or battery value is less than the specified limit value, the algorithm is corrected. If the battery is more than the specified limit value, in this case, the detection is successful, then proceed to the next section. The next process is to add fault detection and isolation using the model-based Kalman Filter method, which can also act as an observer in reducing interference that occurs in the battery. If the detection is successful according to the algorithm, then the next process is continued. If not, then correct the previous process. Then the test results that have been obtained in the test are analyzed. The main thing to observe was to analyze the loading characteristics (voltage), maximum and minimum current data, and the minimum battery charge limit. Several things that must be considered in detecting a battery include: 


\section{- $\quad$ Test Voltage Characteristic}

Testing the characteristics of the battery voltage against the time was carried out during constant loading to determine what the maximum current was and what the maximum load limit that might be used when discharging was, and what the maximum charge limit on the battery when it started to stop discharging so that there was no over-discharge [26][27]. The battery capacity is in excess condition or vice versa, and the minimum battery charge when it should not be used when discharging.

- $\quad$ Test on Current Characteristic

At this maximum current limit, a current characteristic test was also conducted or to determine the maximum current that might pass so that there was no overload or overcurrent in the battery [28][29]. When the load exceeds the specified limit exceeds the maximum current limit, the switch will automatically be turned off to break the connection between the battery and the load.

\subsection{Battery Modelling}

The battery model in Fig. 3 consisted of an ideal battery with an Open Circuit Voltage (OCV) state connected to internal resistance in series, and $V_{t}$ is the battery terminal voltage. The voltage on the OCV was obtained from battery testing on open circuit measurements, while $R$ was obtained based on open circuit measurements and measurements with the load connected to the terminal when the battery was fully charged [30]. This battery model only uses one resistor to show the resistance in it.

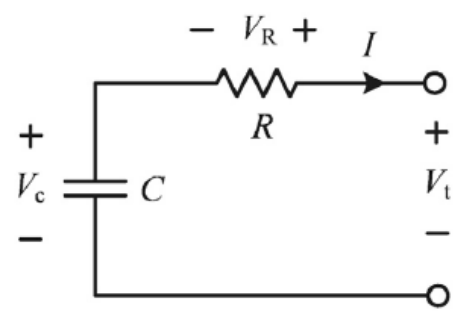

Fig. 3. Battery Modelling

In this study, the following equation analysis was conducted to obtain identification parameters in fault isolation.

$$
\begin{aligned}
& \frac{V_{C}}{V_{t}}=\frac{1}{1+s R C} \\
& \frac{V_{R}}{V_{t}}=\frac{s R C}{1+s R C}
\end{aligned}
$$

The differential equation (1) was conducted with the approach with equation (3), then it obtained equation (4) with $\alpha$ coefficient formulated to equation (5).

$$
\begin{gathered}
\frac{d V_{C}}{d t} \approx \frac{V_{C}[k]-V_{C}[k-1]}{T_{s}} \\
V_{C}[k]=V_{C}[k-1] \cdot(1-\alpha)+V_{t}[k] \cdot \alpha \\
\alpha=\frac{T_{s}}{T_{s}+R C}
\end{gathered}
$$

With the above completion, the connection among voltage, resistance, and current could be transformed into equation (6), and the current information, I, was obtained in equation (7).

$$
\begin{gathered}
\frac{I}{V_{t}}=-\frac{s C}{1+s R C} \\
I[k]=(1-\alpha) \cdot\left(I[k-1]+\frac{V_{t}[k]-V_{t}[k-1]}{R}\right)
\end{gathered}
$$


From the equation, the capacitor voltage showing the battery on OCV was obtained. ECM (Equivalent Circuit Model) is a battery as a capacitor, an ideal voltage source. Then there is a resistor as internal resistance and parallel RC as the polarization characteristics of the battery developed in this study.

\section{RESULTS AND DISCUSSION} following.

In this study, there are several results and a complete discussion with validated test data, including the

\subsection{Optimal Design of Fault Isolation of Battery}

It was a phase to design the fault isolation of battery covering a number of points: testing the battery and detection and isolation of fault itself [31]. In this study, the battery testing was on the discharge test to observe how its characteristics as the battery is a dynamic non-linear or have flexible characteristics and to result in some faults that might occur in a battery.

\subsubsection{Testing in Constant Load}

The test functioned to observe to what extent the capacity of the battery with the constant load that was given at 1C. With a full discharge test until running out, a discharge curve was obtained, which was then analyzed to observe the steep currents or voltage spikes so that the fault was detectable. This fault detection is called over-discharge.

\subsubsection{Test on Pulse}

This test aimed to obtain SOC-OCV data by discharging for 30 seconds or to obtain an accurate OCV sample curve and then was rested for 30 seconds. This was done continuously repeated until the battery was discharged or reached the maximum limit. From this test, the SOC-OCV data were obtained in a full condition until it ran out or the maximum and minimum OCV values were known. Subsequently, it was used as a reference for detecting any faults in the battery as in the detection calculation it requires the maximum and minimum OCV and SOC

\subsubsection{Test on Varied Load}

Test on $1 \mathrm{C}$ discharge was carried out with a maximum battery terminal voltage of $4.23 \mathrm{~V}$ within 6 minutes to get a $10 \%$ reduction in SOC to produce overcurrent due to short circuit with a maximum surge of $10 \mathrm{~A}$ for 10 seconds. Also, during the experiment in collecting the data, the sensor used was highly potential to experience the fault, say, due to the supply cable being broken or accidentally disconnected, leading the data readings to be imperfect. The experiment to obtain sensor failure data used the discharge testing in which half of its operation was in a loaded state (1C) and half of its operation in a no-load state with a duration of 7.5 minutes. The experiment was conducted using a dummy load with a load/current pull of $2.2 \mathrm{~A}$, which then caused a surge in current when experiencing a short circuit and due to sensor failure.

\subsection{Test on SOC-OCV Connection}

This test was conducted with loading of $1 \mathrm{C}$ for one hour to find out the capacity of the full battery state until running out. Based on Fig. 4, the measured terminal voltage is $3.52 \mathrm{~V}$ (when the voltage drops on the curve) under 2.2 A loaded condition with a duration of one hour, and the measured OCV voltage (load disconnected from the battery) is $3.65 \mathrm{~V}$, where the voltage is $3.65 \mathrm{~V}$. It is the voltage at $0 \%$ SOC or capacity runs out. Furthermore, the terminal voltage of $3.52 \mathrm{~V}$ is used as a reference for the minimum working area limit in the battery fault detection study.

Fig. 4 is the current input similar to the pulse test. The battery model could follow the form of the test terminal voltage, indicating that the battery model worked properly. From the relative error, it can be seen that the model was quite accurate, with a mean relative error of $0.06 \%$. The error was quite small; thus, it can be concluded that the parameters that change the battery capacity are quite accurate. The reference value of SOC, $\mathrm{OCV}$, terminal voltage $\left(V_{t}\right)$ is used to detect a fault in the BMS.

- If the SOC value is less than $0 \%$ and the $\mathrm{OCV}$ is less than $3.65 \mathrm{~V}$, an over-discharge occurs.

- If the current value has exceeded the maximum limit of $6 \mathrm{~A}$ and the rated terminal voltage of the battery is less than $3.85 \mathrm{~V}$, an overcurrent occurs.

- If the measured terminal voltage value is in the range of $1 \mathrm{~V}<V_{t}<2 \mathrm{~V}$ between then, there is a sensor reading error or sensor failure. 


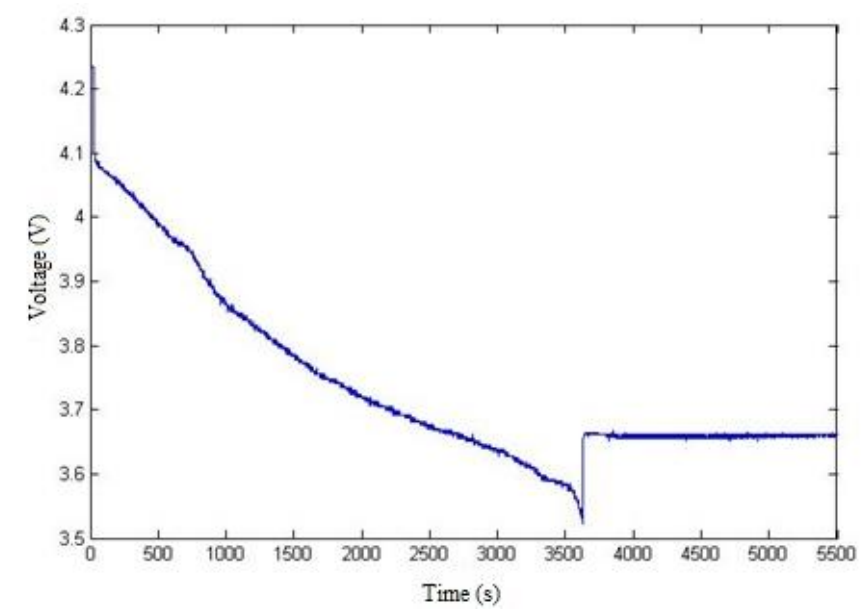

Fig. 4. Battery Voltage Measured with the Constant Load

\subsection{Overcurrent}

Experimental data is data directly obtained from sensors and data from models or simulations that have been made by taking into account several assumptions to facilitate error detection. The results of the comparison of the two data will be improved by applying the Kalman Filter algorithm, which functions to improve the actual reading results. Furthermore, noise elements are added to each type of error which will also be corrected using the Kalman Filter. The comparison of terminal voltage between experiment results of the Kalman filter is shown in Fig. 5.

Kalman Filter is one of the algorithms commonly used in linear systems and as a solution used to solve linear discrete data filtering problems. This method uses a recursive process in handling measurement data that contains a lot of interference or can be said to be noise. It is used in dynamic system estimation. The system assumed by this method is a linear system and estimates the previous state, current state, and future state and can work even when the nature of the system being modeled is not known correctly and precisely. Noise can be caused by the dynamic state of a system, for example, in the battery, namely the dynamic state of the sensor. Random variables representing process noise and measurement noise can change over time or can be set in a constant form.

When the curve is at a value of 0 then it is in a safe condition, or there is no error. On the contrary, if the curve is at a value of 1 then it is in an error condition, or there has been an overload. From the previous overdischarge turtle, we can observe that $V_{t}$ and SOC increase when they are used for too long, namely with Vt and OCV values less than $3.52 \mathrm{~V}$ and SOC exceeding $100 \%$.

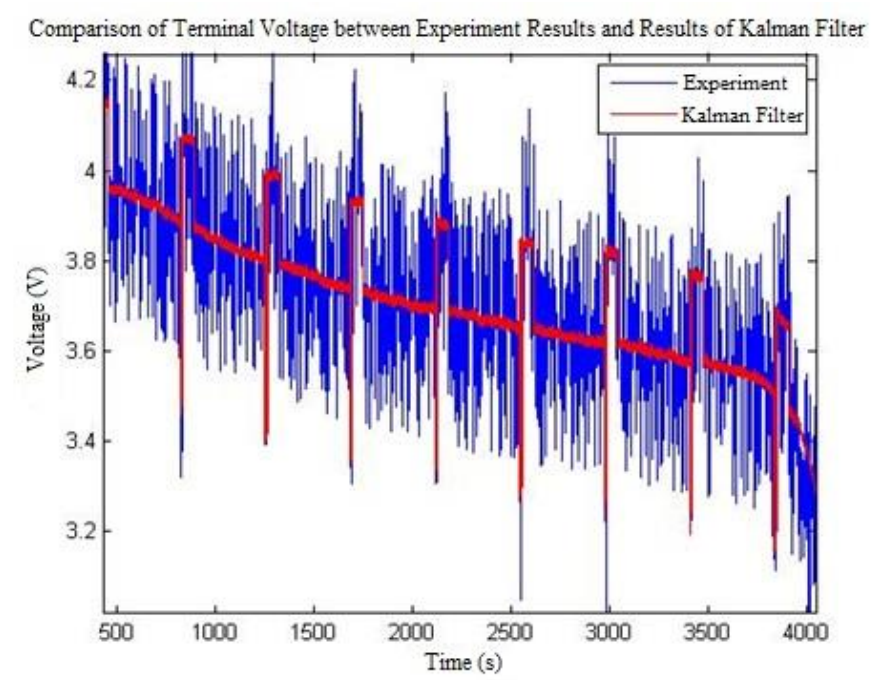

Fig. 5. Overcurrent due to the Noise 
The current and voltage data on the battery cannot be separated from any interference/noise elements that can cause errors that can affect battery life. Fig. 6 shows an overcurrent due to a short circuit affected by noise. From the curve, it can be observed that the Kalman Filter was able to reduce any noise-causing failure in the signal reception system and made the system inefficient.

The detection of overcurrent fault in view of the short circuits resulted in very sharp spikes reaching $3.2 \mathrm{~V}$ from the minimum voltage limit of $3.65 \mathrm{~V}$. Meanwhile, a discharge current of $6 \mathrm{~A}$ from the maximum current limit of $10 \mathrm{~A}$ was obtained. From the test data, the normal value of current of $<6 \mathrm{~A}$ was obtained, and this then caused the battery to occur overcurrent as observed on the detection curve by defining the curve error at the value of 1 . Otherwise, the safe condition of the battery curve is at a value of 0 . Fig. 6 shows that when the battery was short-circuited, then the curve was within the value of 1 .
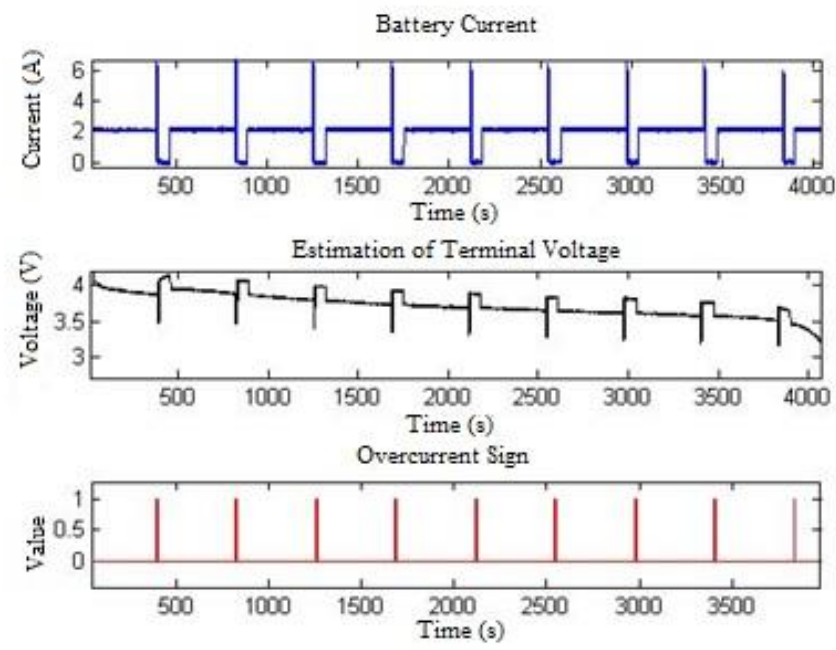

Fig. 6. Detection and Isolation of Overcurrent

\subsection{Sensor Failure}

Testing the battery was conducted through several data collection scenarios, including that the current sensor was considered ideal or maintained to prevent any failure from occurring [32]. This was done because the current was input in the experiment determining the results of the model. The next scenario was that the supply to the sensor circuit leading to the battery was removed, so it could not measure the battery properly, and an error occurred in sensor reading. The experiment was carried out with a load of $1 \mathrm{C}$ within 7 minutes. First, the battery was rested with the no-load condition, and it was discharged with a loaded condition (1C), and in the interval of these conditions, a sensor failure was made with the pattern as shown in Table 2.

Table 2. The Scenario of the Sensor Failure Experiment

\begin{tabular}{cccc}
\hline Battery State & Current Sensor State & Voltage Sensor State & Remark \\
\hline Rest & Normal & Normal & \\
Rest & Normal & Failed & \\
Rest & Normal & Normal & Without load (measuring OCV) \\
Rest & Normal & Normal & \\
Rest & Normal & Normal & \\
Rest & Normal & Failed & \\
Rest & Normal & Normal & \\
Discharged & Normal & Normal & \\
Discharged & Normal & Failed & Loaded \\
Discharged & Normal & Normal & (discharged 1C) \\
Discharged & Normal & Normal & \\
Discharged & Normal & Normal & \\
Discharged & Normal & Failed & \\
Discharged & Normal & Normal & \\
Rest & Normal & Normal & \\
\hline
\end{tabular}


The state of the current sensor was always in a normal state as the current sensor is an important element in data collection referring to the load current, while the voltage sensor is in a failed state due to an improper installation, resulting in a failure in the sensor data reception system. This simulation was carried out with the aim of getting a comparison of the $V_{t}$ sensor fail with the $V_{t}$ output model.

The simulation output of the voltage sensor was obtained by $\mathrm{V}_{t}$ of $1.5 \mathrm{~V}$ to $1 \mathrm{~V}$. As shown in Table 2 , it can be stated that the voltage sensor was in a failed state, while the output of the model was obtained by $V_{t}$ of $3.7 \mathrm{~V}$ to $4 \mathrm{~V}$. Compared with the experimental results, it could be observed that both had almost equal same conditions so that it can be concluded that the two conditions were similar or reliable. Furthermore, the data were added the following noise elements.

This is a form of battery protection or protecting the battery working conditions beyond tolerances or specifications by distinguishing safe or dangerous battery conditions that are useful for optimizing battery performance. It is done so that the battery life is more durable and safer. Fig. 7 illustrates a sensor failure on the battery by adding a fault signal. In the sensor failure test, an additional noise signal was created based upon the sensor fail curve generated by the comparison of the $V_{t}$ sensor fail with the $V_{t}$ output model derived from the voltage sensor, which was then reduced using a Kalman Filter.

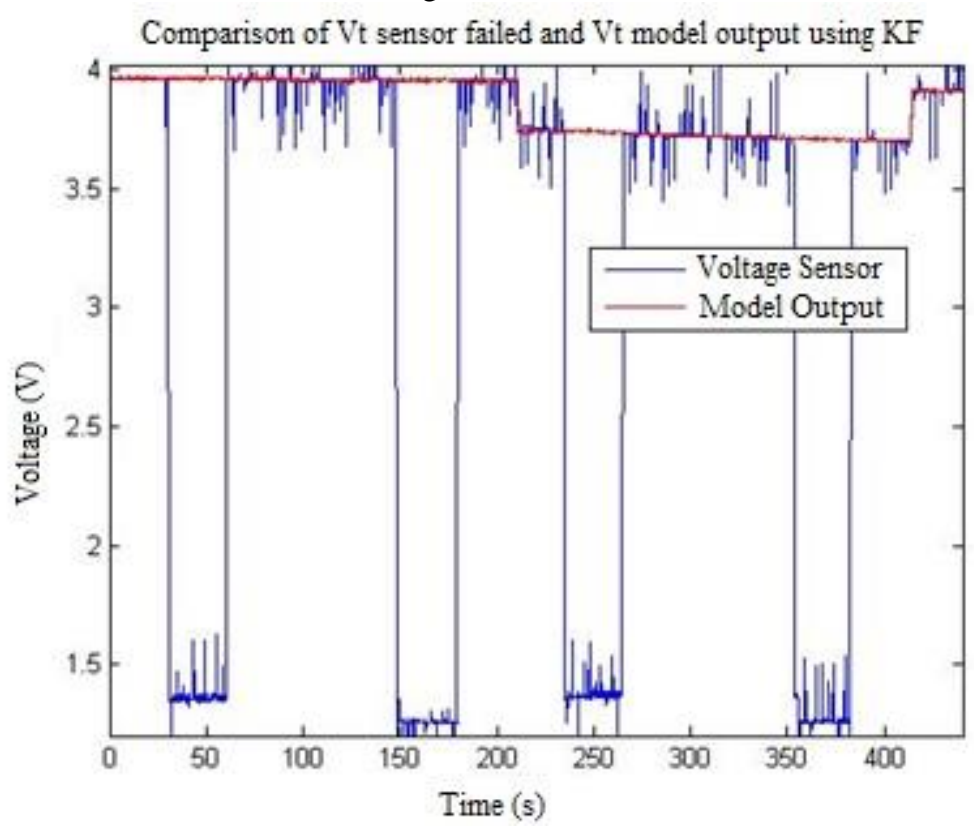

Fig. 7. Sensor Failure due to the Noise using Kalman Filter

Kalman Filter acts as a solution that is used to solve linear discrete data filtering problems where this recursive process is the first. In addition, Kalman Filter has a system that is assumed to be a linear system, and all observed variables are represented in a Gaussian distribution. It supports estimation of the previous state, current state, and future state and can work even when the nature of the system being modeled is not known correctly and precisely.

An important part of the operation of the Kalman Filter algorithm is the recursive process which is divided into two parts, namely the predictor and corrector sections. Predictors function to estimate the next state and error covariance. At the same time, the corrector serves to provide feedback on the state and error covariance in order to obtain better and more accurate state estimation results. In estimating a state, the Kalman Filter can use a form of feedback control by estimating the state process at a time and then getting feedback in the form of measurement results. The results of detection and isolation using the Kalman Filter in Fig. 8 were quite accurate by comparing the $V_{t}$ sensor data with the $V_{t}$ model data. The isolation of sensor failure could be defined if the curve was at a value of 0 and then it was in a safe state (no error), otherwise, if the curve was at a value of 1 , then it was in a failed state, or a sensor failure occurred.

\section{CONCLUSION}

The results of detection and isolation of overcurrent and sensor failure using Kalman Filter were found quite accurate. In overcurrent isolation, a discharge current of $6 \mathrm{~A}$ was obtained from the maximum current limit of $10 \mathrm{~A}$. For sensor failure isolation, the Kalman Filter algorithm succeeded in improving the previous 

Vol. 7, No. 3, December 2021, pp. 412-422

readings or was able to reduce noise. Meanwhile, sensor failure due to the noise produced the reliable state or noise sensor data were minimized, making the current and voltage sensors safe.
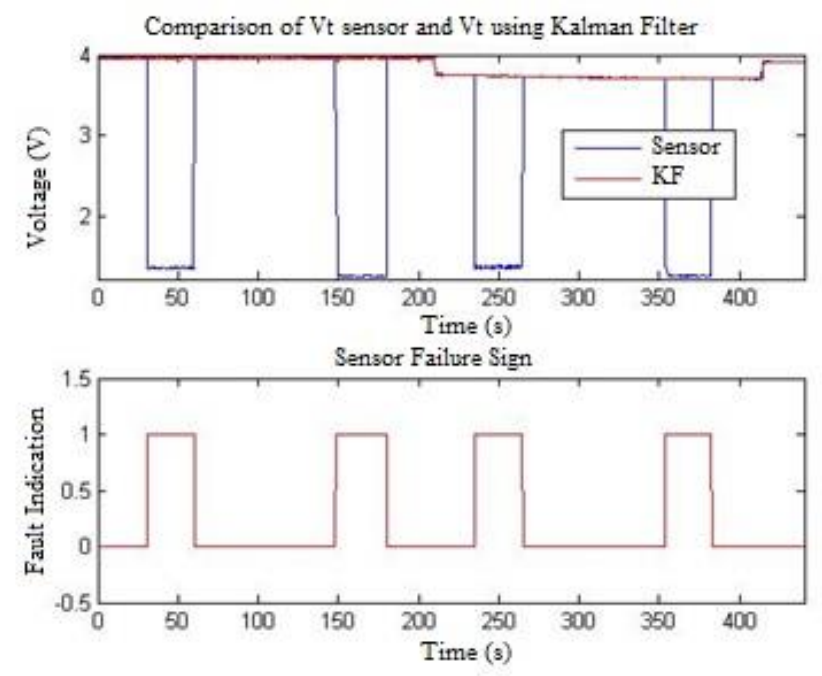

Fig. 8. Detection and Isolation of Sensor Failure using Kalman Filter

\section{Acknowledgments}

This research was funded by Lembaga Penelitian dan Pengabdian kepada Masyarakat, Institut Teknologi Telkom Surabaya.

\section{REFERENCES}

[1] M. Kim, K. Kim, and S. Han, "Reliable Online Parameter Identification of Li-Ion Batteries in Battery Management Systems Using the Condition Number of the Error Covariance Matrix," IEEE Access, vol. 8, pp. 189106-189114, 2020. https://doi.org/10.1109/ACCESS.2020.3031500

[2] Q. Wei, D. Liu, Y. Liu, and R. Song, "Optimal constrained self-learning battery sequential management in microgrid via adaptive dynamic programming," IEEE/CAA J. Autom. Sin., vol. 4, no. 2, pp. 168-176, 2017. https://doi.org/10.1109/JAS.2016.7510262

[3] S. Zeinal-Kheiri, A. M. Shotorbani, and B. Mohammadi-Ivatloo, "Real-time Energy Management of Grid-connected Microgrid with Flexible and Delay-tolerant Loads," J. Mod. Power Syst. Clean Energy, vol. 8, no. 6, pp. 1196-1207, 2020. https://doi.org/10.35833/MPCE.2018.000615

[4] Q. Zhang, W. Deng, and G. Li, "Stochastic Control of Predictive Power Management for Battery/Supercapacitor Hybrid Energy Storage Systems of Electric Vehicles," IEEE Trans. Ind. Informatics, vol. 14, no. 7, pp. 3023-3030, 2018. https://doi.org/10.1109/TII.2017.2766095

[5] Z. Sun, P. Liu, and Z. Wang, "Real-time fault diagnosis method of battery system based on Shannon entropy," Energy Procedia, vol. 105, pp. 2354-2359, 2017. https://doi.org/10.1016/j.egypro.2017.03.676

[6] N. Ullah, Z. Farooq, I. Sami, M. S. Chowdhury, K. Techato, and H. Alkhammash, "Industrial Grade Adaptive Control Scheme for a Micro-Grid Integrated Dual Active Bridge Driven Battery Storage System," IEEE Access, vol. 8, pp. 210435-210451, 2020. https://doi.org/10.1109/ACCESS.2020.3039947

[7] Y. Pan, X. Feng, M. Zhang, X. Han, L. Lu, and M. Ouyang, "Internal short circuit detection for lithium-ion battery pack with parallel-series hybrid connections," J. Clean. Prod., vol. 255, p. 120277, 2020. https://doi.org/10.1016/j.jclepro.2020.120277

[8] X. Kong, Y. Zheng, M. Ouyang, L. Lu, and J. Li, "Fault diagnosis and quantitative analysis of micro-short circuits for lithium-ion batteries in battery packs," J. Power Sources, vol. 395, pp. 358-368, 2018. https://doi.org/10.1016/j.jpowsour.2018.05.097

[9] X. Lai, W. Yi, X. Kong, X. Han, L. Zhou, T. Sun, and Y. Zheng, "Online detection of early stage internal short circuits in series-connected lithium-ion battery packs based on state-of-charge correlation," Journal of Energy Storage, vol. 30, p. 101514, Aug. 2020. https://doi.org/10.1016/j.est.2020.101514

[10] J. Jiang, X. Cong, S. Li, C. Zhang, W. Zhang, and Y. Jiang, "A Hybrid Signal-Based Fault Diagnosis Method for Lithium-Ion Batteries in Electric Vehicles,” IEEE Access, vol. 9, pp. 19175-19186, 2021. https://doi.org/10.1109/ACCESS.2021.3052866

[11] N. Yadav and N. R. Tummuru, "Fault Detection and Isolation Technique in Low Voltage DC Microgrid Based on Terminal Resistance of DC Circuit Breakers," 2020 IEEE International Conference on Power Electronics, Smart Grid and Renewable Energy (PESGRE2020), Jan. 2020. https://doi.org/10.1109/PESGRE45664.2020.9070425

[12] S. M. M. Alavi, S. Fekriasl, S. N. Niyakan, and M. Saif, "Fault detection and isolation in batteries power electronics 
and chargers," Journal of Energy Storage, vol. 25, p. 100807, Oct. 2019. https://doi.org/10.1016/j.est.2019.100807

[13] S. Dey, H. E. Perez, and S. J. Moura, "Robust fault detection of a class of uncertain linear parabolic PDEs," Automatica, vol. 107, pp. 502-510, Sep. 2019. https://doi.org/10.1016/j.automatica.2019.06.014

[14] R. Xiong, W. Sun, Q. Yu, and F. Sun, "Research progress, challenges and prospects of fault diagnosis on battery system of electric vehicles," Appl. Energy, vol. 279, no. 2, p. 115855, 2020. https://doi.org/10.1016/j.apenergy.2020.115855

[15] J. Zhang, "A Model-Based Method for Fault Detection and Isolation of Electric Drive Systems," 2020 IEEE International Conference on Prognostics and Health Management (ICPHM), 2020. https://doi.org/10.1109/ICPHM49022.2020.9187028

[16] Y. Kang, B. Duan, Z. Zhou, Y. Shang, and C. Zhang, "A multi-fault diagnostic method based on an interleaved voltage measurement topology for series connected battery packs," J. Power Sources, vol. 417, pp. 132-144, 2019. https://doi.org/10.1016/j.jpowsour.2019.01.058

[17] L. Yao, Z. Fang, Y. Xiao, J. Hou, and Z. Fu, "An Intelligent Fault Diagnosis Method for Lithium Battery Systems Based on Grid Search Support Vector Machine," Energy, vol. 214, p. 118866, Jan. 2021. https://doi.org/10.1016/j.energy.2020.118866

[18] H. Aung, J. J. Soon, S. T. Goh, J. M. Lew, and K. S. Low, "Battery Management System with State-of-Charge and Opportunistic State-of-Health for a Miniaturized Satellite," IEEE Trans. Aerosp. Electron. Syst., vol. 56, no. 4, pp. 2978-2989, 2020. https://doi.org/10.1109/TAES.2019.2958161

[19] C. Zheng, Z. Chen, and D. Huang, "Fault diagnosis of voltage sensor and current sensor for lithium-ion battery pack using hybrid system modeling and unscented particle filter," Energy, vol. 191, p. 116504, Jan. 2020. https://doi.org/10.1016/j.energy.2019.116504

[20] Y. C. H. Yuwono, B. R. Dewangga, A. I. Cahyadi, and S. Herdjunanto, "Fault Detection on The Battery SOC-OCV by Using Observer," 2018 4th Int. Conf. Sci. Technol., pp. 1-4, 2018. https://doi.org/10.1109/ICSTC.2018.8528607

[21] A. Dhoke, R. Sharma, and T. K. Saha, "A technique for fault detection, identification and location in solar photovoltaic systems,” Sol. Energy, vol. 206, pp. 864-874, 2020. https://doi.org/10.1016/j.solener.2020.06.019

[22] J. Meng, M. Boukhnifer, and D. Diallo, "On-line Model-based Short Circuit Diagnosis of Lithium-Ion Batteries for Electric Vehicle Application," IECON 2019 - 45th Annual Conference of the IEEE Industrial Electronics Society, 2019, pp. 6022-6027. https://doi.org/10.1109/IECON.2019.8927671

[23] A. Naha, A. Khandelwal, K. S. Hariharan, A. Kaushik, A. Yadu, and S. M. Kolake, "On-Board Short-Circuit Detection of Li-ion Batteries Undergoing Fixed Charging Profile as in Smartphone Applications," IEEE Transactions on Industrial Electronics, vol. 66, no. 11, pp. 8782-8791, Nov. 2019. https://doi.org/10.1109/TIE.2018.2889623

[24] Q. Xue, G. Li, Y. Zhang, S. Shen, Z. Chen, and Y. Liu, "Fault diagnosis and abnormality detection of lithium-ion battery packs based on statistical distribution," Journal of Power Sources, vol. 482, p. 228964, Jan. 2021. https://doi.org/10.1016/j.jpowsour.2020.228964

[25] R. Xiong, Q. Yu, W. Shen, C. Lin, and F. Sun, "A Sensor Fault Diagnosis Method for a Lithium-Ion Battery Pack in Electric Vehicles," IEEE Transactions on Power Electronics, vol. 34, no. 10, pp. 9709-9718, Oct. 2019. https://doi.org/10.1109/TPEL.2019.2893622

[26] W. Gao, X. Li, M. Ma, Y. Fu, J. Jiang, and C. Mi, "Case Study of an Electric Vehicle Battery Thermal Runaway and Online Internal Short-Circuit Detection," IEEE Transactions on Power Electronics, vol. 36, no. 3, pp. 2452-2455, Mar. 2021. https://doi.org/10.1109/TPEL.2020.3013191

[27] X. Fan, W. Zhang, Z. Wang, F. An, H. Li, and J. Jiang, "Simplified Battery Pack Modeling Considering Inconsistency and Evolution of Current Distribution," IEEE Trans. Intell. Transp. Syst., vol. 22, no. 1, pp. 630-639, 2021. https://doi.org/10.1109/TITS.2020.3010567

[28] H. Rozas, R. M. Claveria, M. E. Orchard, and K. Medjaher, "Residual-based scheme for detection and characterization of faults in lithium-ion batteries," IFAC-PapersOnLine, vol. 51, no. 24, pp. 200-207, 2018. https://doi.org/10.1016/j.ifacol.2018.09.578

[29] Z. Chen, K. Xu, J. Wei, and G. Dong, "Voltage fault detection for lithium-ion battery pack using local outlier factor," Measurement, vol. 146, pp. 544-556, Nov. 2019. https://doi.org/10.1016/j.measurement.2019.06.052

[30] R. Yang, R. Xiong, H. He, and Z. Chen, "A fractional-order model-based battery external short circuit fault diagnosis approach for all-climate electric vehicles application," Journal of Cleaner Production, vol. 187, pp. 950-959, Jun. 2018. https://doi.org/10.1016/j.jclepro.2018.03.259

[31] Z. Song, F. P. Delgado, J. Hou, H. Hofmann, and J. Sun, "Individual Cell Fault Detection for Parallel-Connected Battery Cells Based on the Statistical Model and Analysis," 2020 American Control Conference (ACC), 2020, pp. 1155-1160. https://doi.org/10.23919/ACC45564.2020.9147423

[32] Z. B. Omariba, L. Zhang, and D. Sun, "Review of Battery Cell Balancing Methodologies for Optimizing Battery Pack Performance in Electric Vehicles," IEEE Access, vol. 7, pp. 129335-129352, 2019. https://doi.org/10.1109/ACCESS.2019.2940090 


\section{BIOGRAPHY OF AUTHORS}

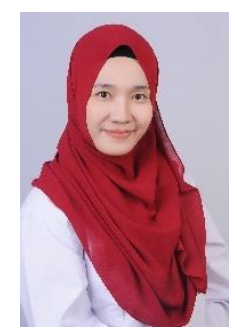

Lora Khaula Amifia, was born in Mojokerto, East Java, Indonesia, on June 06, 1992. She is a Lecturer in the Faculty of Electrical Engineering and Intelligent Industry, Institut Teknologi Telkom Surabaya, Indonesia. She received an S. Pd degree from the State University of Malang, Malang, Indonesia, in 2014. She did M.Eng. degree at in Universitas Gadjah Mada, Yogyakarta, Indonesia in 2016 and her research interests are Control Engineering, Non Linear System, Artificial Intellegent. Email: loraamifia@ittelkom-sby.ac.id

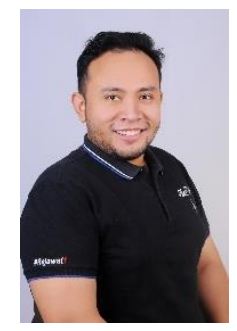

Nuansa Dipa Bismoko, was born in Mataram, West Nusa Tenggara, Indonesia, on August 04, 1991. He is an Officer IoT Smart Connectivity in PT. Telekomunikasi Seluler (Telkomsel), Indonesia. In 2014-2016, he earned a Bachelor's and a Master's degree in Electrical Engineering from Institut Teknologi Sepuluh Nopember (ITS) in Surabaya, Indonesia. His research focuses on the Internet of Things (IoT) control center management and product. Email: nuansa_d_bismoko@telkomsel.co.id

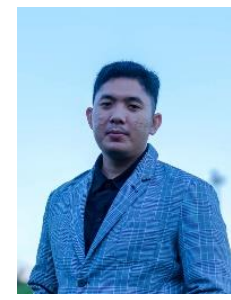

Philip Tobianto Daely, was born in Medan, Indonesia, in 1994. He received his B.Eng. degree in electrical engineering from Telkom University, Bandung, Indonesia, in 2015 and the M.Eng. degree in IT convergence engineering from Kumoh National Institute of Technology, Gumi, South Korea, in 2017. He is currently on leave as a Lecturer in the Department of Information Technology, Institut Teknologi Telkom Surabaya, Surabaya, Indonesia, to pursue a Ph.D. degree in Kumoh National Institute of Technology. His research interests include wireless localization, vehicle routing problem optimization, and industrial internet of things application. Email: philip.daely@kumoh.ac.kr 